\title{
Composição da comunidade bacteriana cutânea em anfíbios na região Oeste do Pará, Amazônia, Brasil
}

O tecido cutâneo dos anfíbios é fundamental em muitos aspectos de sua vida. As características naturais da pele de um anfíbio fornecem um microambiente ideal para o crescimento de microrganismos diversos que auxiliam em muitos processos importantes para os hospedeiros. Portanto, o presente estudo teve como objetivo caracterizar a microbiota cutânea cultivável de anfíbios amostrados na região de Santarém, Oeste do Pará, Amazônia, Brasil. Para isso os anfíbios foram capturados em buscas ativas em horário noturno, entre os meses de novembro de 2017 a abril de 2019 . 0 material cutâneo foi colhido por esfregaço na região dorsoventral do animal, utilizando um swab embebido em solução salina 0,85\% até a diluição 10-3, e cultivado em placas de Petri contendo meio PCA Posteriormente, o isolamento das colônias foi realizado de acordo com os morfotipos das bactérias e a identificação das cepas foi realizada por chave bioquímica para identificação ao menor nível taxonômico. Foram capturadas duas espécies de anfíbios, totalizando 25 indivíduos, sendo 15 exemplares de Rhinella major e 10 indivíduos de Rhinella marina. Foram identificadas 101 cepas bacterianas e destas 94\% foram de bactérias Gram-positivo. Os gêneros bacterianos mais representativos em ambas as espécies de anfíbios foram Corynebacterium, Lactobacillus e Mycobacterium. Ainda que alguns gêneros de bactérias identificadas nesse estudo possuam espécies que sejam caracterizadas como potenciais agentes patogênicos, não foram encontrados indícios de que estariam causando danos aos animais estudados. Desse modo, é importante que novos estudos sejam realizados com o objetivo de sublimar e inspecionar a microbiota de anfíbios.

Palavras-chave: Anuros; Rhinella; Bactérias; Microbiota; Pele.

\section{Composition of the cutaneous bacterial community in amphibians in the Western region of Pará, Amazon, Brazil}

\begin{abstract}
The cutaneous tissue of amphibians is fundamental in many aspects of their lives. The natural characteristics of an amphibian's skin provide an idea microenvironment for the growth of diverse microorganisms that assist in many important processes for hosts. Therefore, the present study aimed to characterize the cultivable cutaneous microbiota of amphibians sampled in the Santarém region, Western of Pará, Amazonia, Brazil. For this, the amphibians were captured in active searches at night, between the months of November 2017 to April 2019. The cutaneous material was collected by smear in the dorsoventral region of the animal, using a swab soaked in $0.85 \%$ saline until dilution $10-3$, and cultured in Petri dishes containing PCA medium. Subsequently, the isolation of the colonies was carried out according to the bacterial morphotypes and the identification of the strains was carried out using a biochemical key to identify until the lowest taxonomic level. Two species of amphibians were captured, totaling 25 individuals, being 15 specimens of Rhinella major and 10 individuals of Rhinella marina. 101 bacterial strains were identified and of these $94 \%$ were Gram-positive bacteria. The most representative bacterial genera in both amphibian species were Corynebacterium, Lactobacillus and Mycobacterium. Although some genera of bacteria identified in this study have species that are characterized as potential pathogens, there was no evidence that they were causing damage to the animals studied. Thus, it is important that further studies are carried out with the aim of sublimating and inspecting the amphibian microbiota.
\end{abstract}

Keywords: Anurans; Rhinella; Bacteria; Microbiota; Skin.

Topic: Desenvolvimento, Sustentabilidade e Meio Ambiente

Reviewed anonymously in the process of blind peer.
Received: 05/10/2020

Approved: $\mathbf{2 6 / 1 1 / 2 0 2 0}$
Andreza da Silva Peixoto (iD

Universidade Federal do Oeste do Pará, Brasil

http://lattes.cnpq.br/2222990032367605

http://orcid.org/0000-0003-0740-8386

andrezapeixoto9@gmail.com

Daniel de Sousa Guedes (ic)

Universidade Federal do Oeste do Pará, Brasil

http://lattes.cnpq.br/2870700407247484

http://orcid.org/0000-0002-9168-8757

danielguedesstm@gmail.com

Andresa Krislany Ferreira (iD

Universidade Federal do Oeste do Pará, Brasil

http://lattes.cnpq.br/2342554663780207

http://orcid.org/0000-0001-5413-3077

andresa.krislany@yahoo.com.br

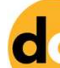

DOI: $10.6008 / C B P C 2179-6858.2020 .006 .0034$

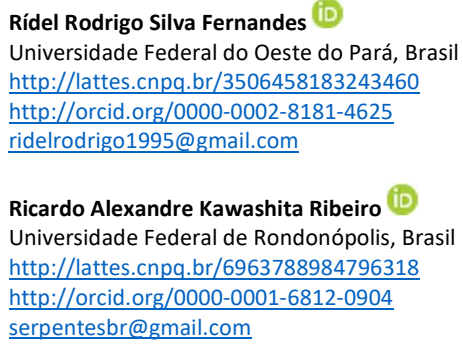

Rídel Rodrigo Silva Fernandes (iD

Universidade Federal do Oeste do Pará, Brasil

http://lattes.cnpq.br/3506458183243460

http://orcid.org/0000-0002-8181-4625

ridelrodrigo1995@gmail.com

Ricardo Alexandre Kawashita Ribeiro (i)

Universidade Federal de Rondonópolis, Brasil

http://lattes.cnpq.br/6963788984796318

http://orcid.org/0000-0001-6812-0904

serpentesbr@gmail.com

Graciene do Socorro Taveira Fernandes (iD)

Universidade Federal do Oeste do Pará, Brasil

http://lattes.cnpq.br/9121021285937589

http://orcid.org/0000-0002-2710-4251

gracienefernandes@hotmail.com

\section{Referencing this:}

PEIXOTO, A. S.; GUEDES, D. S.; FERREIRA, A. K.; FERNANDES, R. R. S.; RIBEIRO, R. A. K.; FERNANDES, G. S. T.. Composição da comunidade bacteriana cutânea em anfíbios na região Oeste do Pará, Amazônia, Brasil. Revista Ibero Americana de Ciências Ambientais, v.11, n.6, p.411-427, 2020. DOI: http://doi.org/10.6008/CBPC2179- 


\section{INTRODUÇÃO}

Os anfíbios têm importante papel ecológico no transporte de energia de ambientes aquáticos e terrestres, e vários fatores têm contribuído para o declínio de sua população (CATENAZZI, 2015; SCHEELE et al., 2019). Entre as ameaças à sobrevivência destes animais estão, perda de habitat, poluição, comércio como animais de estimação, mudanças climáticas e doenças infecciosas emergentes (SCHIPPER et al., 2008).

O tecido cutâneo dos anfíbios é fundamental em muitos aspectos de sua vida, pois é o principal local de troca dos gases respiratórios (POUGH et al., 2008). Além da respiração cutânea, a pele desses animais desempenha outras funções importantes como barreira imunológica, osmorregulação e termorregulação (COLOMBO et al., 2015). Dentre os vertebrados, os anfíbios apresentam a pele com características únicas e que atua de forma bastante interativa e funcional entre o organismo e o meio externo (ASSIS, 2015).

A maioria dos estudos de microbioma cutâneo dos animais vertebrados das últimas décadas tem se concentrado em seres humanos, animais domésticos e anfíbios (ROSS et al., 2019). A pele dos anfíbios, apesar de ser considerado um sistema incompleto de defesa, é o modelo para doenças que afetam a mucosa dos vertebrados e o muco e seus compostos vem complementar essa barreira. O muco, produzido tanto pelas glândulas dérmicas dos sapos quanto pela comunidade microbiana residente, contém fatores interdependentes do hospedeiro (anticorpos das mucosas, peptídeos antimicrobianos, lisozima, alcaloides) e fatores da comunidade microbiana (metabólitos antibióticos) contribuindo com funções como comunicação e defesa contra predadores e patógenos (SANTOS, 2013; WOODHAMS et al., 2014; SABINOPINTO et al., 2016).

As características naturais da pele de um anfíbio - umidade, composição química do muco e de outras secreções - fornecem um microambiente ideal para o crescimento de microrganismos diversos, alguns dos quais podem estar presentes durante toda a vida destes animais, e outros que podem ser continuamente trocados entre as renovações da pele, estágio de vida, e através do meio ambiente, incluindo os patogênicos (BELDEN et al., 2007; CULP et al., 2007; BOS et al., 2009).

Os animais indistintamente hospedam diversas comunidades microbianas e possuem associações com microrganismos comensais e mutualistas (CULP et al., 2007). Esses microrganismos e suas interações e contribuições, é denominado microbioma e fornecem muitos processos importantes para os hospedeiros (MCFALL-NGAl et al., 2013). Como resultado dessas associações, é comum ocorrer uma dependência dos animais com esses microrganismos em processos vitais críticos, tais como digestão, aquisição de energia e resistência a patógenos. Além disso, a comunidade microbiana presente no tecido cutâneo também auxilia na ação do sistema imune (ROSENBERG et al., 2007; NOLASCO, 2016). Segundo Hughey et al. (2017) espécies animais que obtêm microrganismos simbiontes de fontes ambientais, variação nas condições ambientais afetam o pool microbiano e podem alterar a composição e, em última análise, a função dessas comunidades.

No Brasil, são escassas informações biológicas para muitas espécies de anfíbios, que são divididos em três ordens: Anura, Urodela ou Caudata e Gymnophiona, sendo a ordem Anura a mais abundante (POUGH et al., 2008; PELOSO et al., 2019). A ordem Anura, que tem como representantes os sapos, as rãs e as 
pererecas, é a mais representativa dentre as demais ordens e no Brasil há descritas 1.143 espécies distribuídas em 20 famílias com 106 gêneros (FROST, 2020). O gênero Rhinella Fitzinger, 1826, pertencente à família Bufonidae, é constituído de 92 espécies e é distribuído pelas Américas do Sul e Central, habitando tanto áreas abertas quanto as florestas (FROST, 2020).

A espécie Rhinella major Müller e Hellmich, 1936 é um animal de tamanho diferente de acordo com o sexo, sendo a média dos machos de 54,3 mm e das fêmeas 57,5 mm (NARVAES et al., 2009). É uma espécie com hábitos noturnos, que vive e se alimenta quase exclusivamente em habitats terrestres e geralmente está associada a ambientes antropogênicos (HAMANN et al., 2015).

Rhinella marina Linnaeus, 1758 é uma espécie de grande porte, antigamente conhecida por "Bufo marinus", e no Brasil é popularmente conhecida como "sapo cururu". A R. marina vive em áreas caracterizadas pela cobertura florestada e por áreas abertas, que frequentemente são perturbadas, além disso, esta espécie é bem adaptada à vida urbana (ZUG et al., 1979).

A comunidade bacteriana simbionte em anuros pode nos fornece importantes informações em vários aspectos. A identificação de microrganismos presente na pele de anfíbios, e estudar suas relações sob o aspecto da capacidade de proteção e mutualismo que a comunidade microbiana oferece ao produzir metabólitos contra patógenos, tem sido o alvo de muitas pesquisas. Esses estudos são essenciais para propor estratégias de proteção dos animais contra doenças infecciosas, além de abrir possibilidades para a identificação de substâncias com potenciais usos biotecnológicos e aplicações diversas para o homem e outros animais. Atualmente, tem sido descoberto um emergente aparecimento de doenças infecciosas nesse grupo animal e tem causado declínio de diversas populações de anfíbios ao redor do mundo, incluindo no Brasil, e variáveis ambientais e antrópicas tem sido apontadas como as principais (CAMPBELL, 1999; GREEN et al., 2002; ETEROVICK et al., 2005; ARAÚJO et al., 2006; MITCHELL et al., 2007; SKERRATT et al., 2007; BECKER et al., 2011; VERDADE et al., 2012; BERGER et al., 2016; CARVALHO et al., 2017; SCHEELE et al., 2019).

Portanto, a busca e identificação de bactérias cultiváveis presentes na pele de anfíbios na região amazônica, e quais as relações que ocorrem frente à capacidade de proteção e mutualismo que estes microrganismos oferecem aos animais, podem trazer informações essenciais sobre os processos que estão em vigor, quais os benefícios provenientes dessa relação, e de que forma o resultado dessas associações pode ser utilizado nas diversas áreas de conhecimento.

Desse modo, o presente estudo teve como objetivo caracterizar a microbiota cutânea cultivável de anfíbios na região de Santarém, Oeste do Pará, Amazônia, Brasil.

\section{MATERIAIS E MÉTODOS}

\section{Área de Estudo e Coleta dos Animais}

O estudo foi desenvolvido na área portuária da Universidade Federal do Oeste do Pará, na Unidade

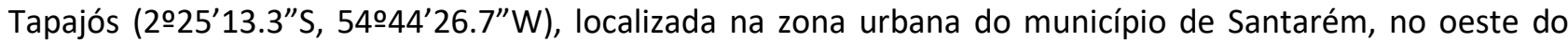
Estado do Pará (Figura 1). 




Figura 1: Imagem de satélite da Unidade Tapajós - UFOPA, na cidade de Santarém, PA. Fontes: Google Maps, 2019.

Os anfíbios foram capturados com a utilização de luvas estéreis, um par para cada animal, por buscas ativas em horário noturno, entre os meses de novembro de 2017 a abril de 2019. Durante a captura, não houve distinção de sexo, e após a captura os exemplares foram transportados em sacos plásticos do tipo ziplock transparentes para o Laboratório de Bacteriologia (LaBac) da UFOPA para os procedimentos de coleta do material cutâneo destes animais.

Após a obtenção do esfregaço foi feita a eutanásia dos espécimes com injeção intracraniana de lidocaína a $2 \%$ via foramen magnum (SEBBEN, 2007), seguido de fixação com formol 10\% e depósito na coleção de anfíbios da UFOPA.

\section{Coleta do Material Microbiano}

No LaBac, o material cutâneo foi colhido por esfregaço na região dorsoventral do animal, utilizando um swab embebido em solução salina $0,85 \%$ estéril, que foi imediatamente colocado em um tubo de ensaio contendo $9 \mathrm{~mL}$ de solução salina 0,85\% estéril. Posteriormente, o tubo de ensaio com o esfregaço foi agitado vigorosamente, e foram obtidas diluições seriadas até a $10^{-3} \mathrm{com}$ três séries de três tubos cada diluição com $9 \mathrm{~mL}$ de solução salina $0,85 \%$ estéril. Feito isto, o material foi inoculado pela técnica de spread plate, em placas de petri contendo o meio de cultura Plate Count Agar (Difco ${ }^{\circ}$ ) em duplicata e incubado em estufa bacteriológica à $37^{\circ} \mathrm{C}$ por 24 a 48 horas.

\section{Obtenção dos Isolados e Identificação Bioquímica}

Após o cultivo do inóculo, foi realizada a contagem registrada em UFC/mL e o isolamento das colônias foi realizado de acordo com os morfotipos das colônias de bactérias heterotróficas até completar as 48 horas de incubação a 370 C. A purificação bacteriana se deu em meio Ágar Triptona Soja (TSA-BD ${ }^{\circ}$ ) com incubação 370 C por $24 \mathrm{~h}$, seguida de teste tintorial pela coloração de Gram, microscopia e descrição de morfologia. Confirmado isolamento e pureza da cultura, estas cepas foram conservadas sob refrigeração para posterior análise.

A identificação das cepas foi realizada por chave bioquímica, após a reativação em meio TSA, e envolveu teste de anaerobiose, catalase, fermentação em Ágar Manitol, hidrólise de esculina, coloração de Ziehl-Neelsen, teste de oxidase e fermentação de glicose e lactose para identificação ao menor nível taxonômico de acordo com Bergey et al. (2000). 


\section{Análise Estatística}

Para comparar a composição de bactérias entre os períodos sazonais chuvoso e de estiagem foi utilizado o teste $T$, e para comparar a diferença entre os gêneros de bactérias foi utilizado a ANOVA, considerando um nível de significância de $\alpha=0,05$.

\section{RESULTADOS}

Foram capturadas duas espécies de anfíbios da ordem Anura, pertencentes a família Bufonidae, totalizando 25 indivíduos. Dentre estes, 15 exemplares pertenciam a espécie Rhinella major e 10 indivíduos a Rhinella marina.

Foram identificadas 101 cepas bacterianas e destas 94\% foram de bactérias Gram-positivo. Do total de cepas, após a identificação bioquímica formaram um conjunto de 11 gêneros, e 68 cepas foram provenientes de $R$. major que apresentou representantes e todos os táxons listados, em contrapartida, para a espécie $R$. marina das 33 cepas bacterianas isoladas foram identificados 5 gêneros (Tabela 1 ).

Os gêneros bacterianos mais representativos em ambas as espécies de anfíbios foram Corynebacterium, seguido de Lactobacillus e Mycobacterium.

Tabela 1: Números de cepas identificadas (n) e frequência de ocorrência (\%) dos isolados bacterianos da microbiota cutânea de R. major e R. marina.

\begin{tabular}{llllll}
\hline \multirow{2}{*}{ Táxon } & \multicolumn{2}{l}{ Rhinella major } & \multicolumn{2}{c}{ Rhinella marina } & Total (n) \\
\cline { 2 - 6 } & $\mathbf{n}$ & \% & $\mathbf{n}$ & \% & 57 \\
\hline Corynebacterium sp. & 36 & 53 & 21 & 64 & 24 \\
Lactobacillus sp. & 17 & 25 & 7 & 21 & 8 \\
Mycobacterium sp. & 5 & 7 & 3 & 9 & 3 \\
Streptococcus sp. & 2 & 3 & 1 & 3 & 2 \\
Serratia sp. & 2 & 3 & 0 & 0 & 2 \\
Pseudomonas sp. & 1 & 1 & 1 & 3 & 1 \\
Staphylococcus aureus & 1 & 1 & 0 & 0 & 1 \\
Vibrio sp. & 1 & 1 & 0 & 0 & 1 \\
Escherichia coli & 1 & 1 & 0 & 0 & 1 \\
Bacillus sp. & 1 & 1 & 0 & 0 & 101 \\
Clostridium sp. & 1 & 1 & 0 & & \\
\hline Total & 68 & & 33 & & \\
\hline
\end{tabular}

O conjunto de cepas obtidas nos períodos chuvoso $(n=51)$ e de estiagem $(n=17)$ mostraram que não houve diferença significativa entre a composição de bactérias identificadas de $R$. major. Entre os gêneros de bactérias desta mesma espécie de anfíbio, quando comparados sem o fator sazonalidade, mostrou diferença significativa.

Em R. marina, a composição de bactérias identificadas mostrou semelhança entre os períodos sazonais (chuvoso $n=9$ e estiagem $n=24$ ), e não demonstrou diferença significativa, entretanto, quando feita a comparação destas bactérias sem considerar o fator sazonalidade, o resultado demonstrou diferença significativa, o que permite pressupor que a microbiota bacteriana é diferente para o conjunto de isolados cultiváveis identificados bioquimicamente.

Após análise comparativa entre o conjunto de bactérias cultiváveis obtidas por espécies de anuro para o mesmo período sazonal, não houve diferença significativa. 


\section{DISCUSSÃO}

Dos gêneros bacterianos identificados, o Corynebacterium foi o mais abundante encontrado neste estudo. As bactérias desse grupo são amplamente distribuídas no ambiente (solo, água, entre outros), e fazem parte da microbiota indígena da pele e das mucosas de humanos e animais (ALIBI et al., 2017; ARAÚJO et al., 2018). As espécies patogênicas são encontradas em humanos e animais como patógenos ou como contaminantes cutâneos, entretanto, oportunamente, em hospedeiros com sistema imunológico comprometido, causam infecções (EGGELING et al., 2008).

Entre todas as espécies de Corynebacterium isoladas em humanos, destaca-se um grupo de microrganismos potencialmente toxigênicos associados a diferentes processos infecciosos: Corynebacterium diphtheriae, Corynebacterium ulcerans e Corynebacterium pseudotuberculosis (OLIVEIRA et al., 2017). As espécies C. ulcerans e C. pseudotuberculosis também são conhecidas por serem agentes zoonóticos, transmitindo doenças de animais infectados a humanos (WAGNER et al., 2010; DIAS et al., 2011; CORTI et al., 2012; HIRATA JÚNIOR et al., 2015). As espécies não patogênicas desse gênero, principalmente C. glutamicum, possuem aplicações biotecnológicas, sendo utilizadas em processos como fermentação e biossíntese de compostos (OLIVEIRA et al., 2017).

Corynebacterium já foi reportado em outros trabalhos que trataram da comunidade microbiana de anfíbios (BANAS et al., 1988; CULP et al., 2007; MILLER et al., 2009; WENG et al., 2017) e Sigirci et al. (2019) relataram pela primeira vez a espécie C. pseudotuberculosis atuando como patógeno em anfíbios (Lepidobatrachus laevis), causando um abscesso no sapo de um zoológico em Istambul. Os resultados encontrados por estes autores demonstram que anfíbios de vida livre apesar de terem menor susceptibilidade a infecções por bactérias do gênero Corynebacterium, aqueles mantidos em cativeiro podem estar sujeitos a esse estado clínico, proveniente de fatores externos ou internos.

O Lactobacillus, é comumente encontrado na microbiota vaginal de humanos, e colonizam outras partes do corpo, como cavidade oral e trato intestinal de humanos e de outros animais (TEUBER, 1993; LEITÃO et al., 2008; TADDEl et al., 2015). As espécies desse gênero geralmente não são patogênicas, no entanto, em casos em que há baixa imunidade aliada a alterações ambientais e corporais, entre outros fatores, podem ser causadoras de infecções (TEUBER, 1993; SOPER, 1999; NESS et al., 2002).

As bactérias do gênero Lactobacillus são conhecidas por possuírem propriedades antimicrobianas protegendo o hospedeiro contra infecções, e os probióticos são amplamente utilizados em humanos e em animais (CASAS et al., 2000; RÖNNQVIST et al., 2006; VANDEPLAS, 2010; MASTROMARINO et al., 2013; TADDEl et al., 2015).

Existem estudos em que os resultados demonstram ter isolado bactérias do gênero Lactobacillus como parte da comunidade microbiana de diversos anfíbios (BANAS et al., 1988; PASTERIS et al., 2006; MENDOZA et al., 2012; BLETZ et al., 2017; WENG et al., 2017; YU et al., 2019). Pasteris et al. (2009) isolaram espécies de Lactobacillus em anfíbios, e observaram potencial antimicrobiano em algumas destas espécies contra patógenos que causam a doença "red leg" nestes animais. Segundo Mendoza et al. (2012) após 
identificar e testar cepas de Lactobacillus spp. de anfíbios, afirmaram que estas bactérias são benéficas e possuem propriedades para serem utilizadas pela indústria como probiótico. Dessa forma, é possível pressupor que este gênero faz parte da microbiota natural dos anfíbios e que pode agir como agente benéfico para estes animais, além das aplicações biotecnológicas (NIEDERLE et al., 2019).

O gênero Mycobacterium compreende organismos que são verdadeiros patógenos, patógenos oportunistas e saprófitos. A grande maioria das espécies podem ser encontradas em diferentes ambientes, como solo e água ou outras fontes ambientais, e apenas algumas espécies são patogênicas ao ser humano (LABOMBARDI, 2008). Dentre as espécies de destaque quanto a importância clínica, estão M. tuberculosis, $M$. bovis e $M$. africanum, causadoras de tuberculose e $M$. leprae (hanseníase). Outras espécies como $M$. ulcerans, M. avium, M. haemophilum, M. kansaii, M. xenopi, entre outras, são patogênicas ou potencialmente patogênicas, humanas e animais (DUCATI et al., 2015).

Para os anfíbios é relatado três espécies causadoras de infecções, $M$. marinum, $M$. xenopi e $M$. ranae. As infecções causadas por micobactérias em anfíbios são relatadas como comuns em animais em cativeiro e com sistema imune comprometido, ou seja, nos animais afetados a presença desta bactéria deve-se a diminuição de suas defesas imunológicas (RONDA et al., 2006; KLAPHAKE, 2009).

O potencial de transmissão zoonótica de micobactérias de anfíbios para humanos tem importantes implicações de saúde pública, especialmente em situações envolvendo frequente e prolongado contato humano com anfíbios em condições de locais lotados, como o ambiente de pesquisa. No entanto, é importante distinguir entre micobactérias simplesmente isoladas de anfíbios e micobactérias patogênicas de anfíbios (CHAl, 2011). Embora muitas espécies de Mycobacterium sejam conhecidamente patogênicas, a deteç̧ão deste microrganismo em compartimentos de animais não caracteriza necessariamente doenças (AGUDELO et al., 2008). Além disso, há evidências de que animais ectotérmicos possuem uma maior resistência natural contra estas bactérias do que animais homeotérmicos, uma vez que este microrganismo é comum em ambiente aquático (KLAPHAKE, 2009).

O gênero Streptococcus faz parte da microbiota indígena de animais, incluindo o homem, e algumas espécies são responsáveis por uma variedade de manifestações clínicas sendo consideradas importantes agentes infecciosos. Além da importância médica deste gênero, para a indústria este microrganismo tem sido essencial na indústria de lacticínios e como indicadores de poluição. Do ponto de vista ecológico, esses microrganismos são amplamente distribuídos e encontrados nos mais diferentes ambientes (TEIXEIRA et al., 2015).

As espécies Streptococcus pyogenes, Streptococcus pneumoniae, Streptococcus agalactiae e estreptococos dos grupos B e C são os patógenos mais prevalentes isolados de humanos (FISCHETTI et al., 2008). Do ponto de vista veterinário, a maior parte das espécies de Streptococcus vive em comensalismo nos tratos respiratório superior, digestivo e genital inferior de animais (BIBERSTEIN et al., 2012a). Em relação a anfíbios, este gênero já foi identificado em alguns estudos com animais de vida livre e de criações em cativeiro (BANAS et al., 1988; PILARSKI et al., 2010; MENDOZA et al., 2012; BLETZ et al., 2017; YU et al., 2019).

O gênero Serratia é caracterizado por espécies que habitam diferentes habitats, como água, solo, 
plantas, animais, e ambientes hospitalares (GRIMONT et al., 2006). Este gênero já foi associado como patogênico em animais de sangue frio, como causador de infecção nodular em lagarto (DURAN-REYNALS et al., 1937); abcessos subcutâneos em iguanas (BOAM et al., 1970); artrite no lagarto Tupinambis tequixin (ACKERMAN et al., 1971); e doença ulcerativa na tartaruga pintada Chrysemys picta (JACKSON et al., 1976).

Quanto aos anfíbios, experimentalmente Rana pipiens e Bufo americanus mostraram susceptibilidade a infecções causadas por Serratia anolium (CLAUSEN et al., 1937). Foi registrado pela primeira vez em anfíbio infecção em axolote (Ambystoma mexicanum), causada por Serratia marcescens, que resultou em septicemia e a morte do animal (DEL-POZO et al., 2011). No entanto, apesar de algumas espécies de Serratia serem potenciais causadoras de infecções em anfíbios e répteis, esse gênero faz parte da microbiota natural de animais (WOODHAMS et al., 2007a; WALKE et al., 2011; HEYNOL et al., 2015; NOWAKIEWICZ et al., 2015; DOUGLAS et al., 2017; PEREIRA et al., 2017; PIOVIA-SCOTT et al., 2017).

O gênero Serratia é caracterizado como potencialmente importante inibidor de infecção pelo fungo Batrachochytrium dendrobatidis patógeno dos anfíbios, relatado por Woodhams et al. (2014) que demonstrou que Serratia plymuthica apresentou capacidade de inibição de crescimento do fungo em diferentes temperaturas. Segundo Madison et al. (2017) a espécie $S$. marcescens isolada de anfíbios também demonstrou propriedades antimicrobianas frente a $B$. dendrobatidis, além de apresentar diversas mudanças transcriptômicas em resposta ao patógeno. Além destes, outras pesquisas mostraram resultado semelhante, em que o gênero Serratia tem ação benéfica para os anfíbios em relação ao $B$. dendrobatidis (WOODHAMS et al., 2007b; ANTWIS et al., 2015; BECKER et al., 2015; BRESCIANO et al., 2015; WOODHAMS et al., 2018).

Bactérias do gênero Pseudomonas tem espécies que são importantes em termos médicos (infecções), biotecnológicos e ambientais (na decomposição e biodegradação aeróbica), e são encontradas em gama de nichos, distribuídas no solo, na água, na vegetação e na pele de animais, incluindo seres humanos (GOLEMI-KOTRA, 2008; ÖZEN et al., 2012). Dentre as mais de 200 espécies conhecidas de Pseudomonas, cerca de 25 dessas estão associadas aos seres humanos, sendo a maioria das espécies patogênicas associadas a infecções oportunistas (IGLEWSKI, 1996; ÖZEN et al., 2012). Como é o caso de $P$. aeruginosa, $P$. paucimobilis, $P$. putida, $P$. fluorescens e $P$. acidovorans (TÜMMLER et al., 2014). Outras espécies são patógenas de animais, principalmente peixes e aves, como, $P$. anguilliseptica, $P$. chlororaphis e P. aeruginosa (PEIX et al., 2009).

O gênero Pseudomonas foi identificado como parte da microbiota cutânea, intestinal e tecidual de diversas espécies de anfíbios (BANAS et al., 1988; WOODHAMS et al., 2007a; MILLER et al., 2009; ANTWIS et al., 2014; LOUDON et al., 2014; DOUGLAS et al., 2017; ABARCA et al., 2018). Este gênero, portanto, faz parte da microbiota natural de anfíbios, podendo inclusive servir como um microrganismo antagonista ao desenvolvimento do fungo $B$. dendrobatidis, como é demonstrado por Lam et al. (2010) que observaram em Rana sierra e Rana muscosa, onde $R$. sierra possuía proporções de Pseudomonas muito maior do que $R$. muscosa, e que $R$. muscosa foi extinta dentro de um ano por $B$. dendrobatidis e $R$. sierra foi capaz de persistir contra o fungo por mais seis anos, indicando que este gênero de bactéria pode ter sido a causa pela resistência a sobrevivência de $R$. sierra. 
As espécies do gênero Staphylococcus habitam a pele e superfícies mucosas de humanos e animais. A espécie Staphylococcus aureus identificada neste estudo, é comensal considerada uma das principais colonizadoras da pele e mucosas de humanos e primatas. Esta espécie é considerada tanto como parte da microbiota residente como transeunte, porém pode causar uma variedade de infecções, desde infecções leves na pele até infecções invasivas com risco de vida (SCHNEEWIND et al., 2008; PANTOSTI, 2012).

Embora S. aureus seja bem estudada em humanos e alguns animais, ainda são poucos os estudos que relatam a ocorrência desta e de outras espécies de Staphylococcus em anfíbios (PINHEIRO, 1989; PASTERIS et al., 2006; ROMERO, 2006; CULP et al., 2007; O'ROURKE et al., 2015; NOLASCO, 2016; DOUGLAS et al., 2017). Além disso, apesar de $S$. aureus ter sido associada em alguns estudos como uma das bactérias causadoras da doença "red leg" em anfíbios (PASTERIS et al., 2006), estes animais eram criados em cativeiro, e não há até o presente momento estudos que demonstrem infecções causadas por S. aureus em anfíbios anuros de vida livre. Segundo Pantosti (2012), algumas linhagens de S. aureus podem ter sofrido modificação genética e perdido fatores de virulência em alguns hospedeiros e adquirido novas características.

O gênero Vibrio compreende, atualmente, mais de uma centena de espécies reconhecidas são bactérias Gram-negativas, anaeróbias facultativas, em forma de bastonete curvo. Os membros deste gênero são encontrados geralmente em ambientes aquáticos (marinhos, águas doces e estuarinas), e podem estar associados a organismos que tem este ambiente como habitat (COLWELL et al., 2008; MARIN et al., 2015). Apesar de haver pelo menos 11 espécies de $V$. cholerae patogênicas em humanos (TORTORA et al., 2012), até o presente momento não há registros de espécies de Vibrio causadora de infecção em anfíbios, porém, é citado em literatura a ocorrência de espécies associadas a estes animais (BANAS et al., 1988; MILLER et al., 2009; HACIOGLU et al., 2014; BELDEN et al., 2015; DOUGLAS et al., 2017; YU et al., 2019).

Escherichia coli encontrada neste estudo é uma espécie comensal habitante natural do trato gastrointestinal de mamíferos e outros animais, e pode ser oportunista em quase todas as espécies animais além de estarem presentes no ambiente onde estão inseridos estes organismos (HIRSH, 2012; JANDA et al., 2008). De acordo com Hirsh (2012), o gênero Escherichia é composto por diversas espécies, no entanto, somente $E$. coli é caracterizada como um importante patógeno animal. A ocorrência de $E$. coli neste estudo possivelmente está correlacionada com o ambiente na qual os anfíbios foram capturados, um local que recebe influência direta e indireta de contaminação do homem e outros animais, no entanto, não é descartado a hipótese de que esta espécie possa fazer parte da microbiota natural do animal, pois já foi encontrada em estudos com anfíbios (MILLER et al., 2009; MENDOZA et al., 2012; DOUGLAS et al., 2017).

As bactérias do gênero Bacillus são bastonetes produtores de esporos, aeróbios e gram-positivos que tipicamente habitam se não todos, quase todos os ambientes da biosfera, e são predominantemente encontrados na água e solo (PRIEST, 1993; BIBERSTEIN et al., 2012b). O único patógeno de vertebrados relatado, incluindo seres humanos, é Bacillus antharacis, um parente próximo de $B$. cereus que causa intoxicação alimentar em cães e seres humanos (BIBERSTEIN et al., 2012b). Algumas espécies deste gênero isoladas de anfíbios já foram testadas e demonstraram atividade antimicrobiana, algo de grande importância visto a atual resistência de microrganismos patogênicos aos antibióticos comuns, fornecendo novas 
alternativas para formulação de fármacos com essa propriedade (PUKALA et al., 2006; EBRAHIMIPOUR et al., 2014; LOUDON et al., 2014).

Clostridium é um dos maiores gêneros bacterianos, incluindo mais de 150 espécies validamente descritas. O gênero é composto por bacilos gram-positivos esporulados, alguns anaeróbios obrigatórios, outros aerotolerantes e alguns, raros, não toleram traços de oxigênio. As espécies deste gênero estão amplamente distribuídas na natureza, sendo encontradas no solo, em vegetações, em sedimentos marinhos e no intestino do homem e de outros vertebrados, além de insetos. As espécies são, em sua maioria, avirulentas, embora algumas possam ser isoladas de infecções endógenas, enquanto outras são patógenos reconhecidos pela produção de potentes toxinas (DÜRRE, 2008; BIBERSTEIN et al., 2012c; FERREIRA et al., 2015). Em relação a ocorrência deste gênero bacteriano em anfíbios, foi relatado em alguns poucos estudos como parte da comunidade microbiana destes animais (BANAS et al., 1988; SABINO-PINTO et al., 2016; VARELA et al., 2018).

Apesar de neste estudo não ter sido evidenciado variações na comunidade bacteriana entre o período chuvoso e de estiagem, segundo estudos realizados com comunidades microbianas em anfíbios, as variações ambientais têm ação sob o hospedeiro de forma a alterar a sua homeostasia, a composição do muco e com isso também alterar a composição do microbioma (BRESCIANO et al., 2015; LOKMER et al., 2015; KOHL et al., 2016; ZANEVELD et al., 2016). Desta forma, variação no microbioma da pele de anfíbios provavelmente representa uma interação complexa dos efeitos de ambas condições abióticas e bióticas no hospedeiro e na comunidade simbionte, e estes animais podem servir como indicadores de alterações ambientais e ajudar na predição de riscos ao ambiente e as populações humanas em geral (HUGHEY et al., 2017).

Atualmente, apesar de diversos avanços na ciência e de como essa se propagou em todo o mundo, estudos caracterizando a microbiota cutânea de anfíbios na região amazônica ainda não são tão comumente realizados. A área em que os anfíbios foram coletados recebe influência antrópica por estar localizada em um centro universitário e ao mesmo tempo servir como porto para o aporte embarcações de médio porte. Além disso, a microbiota cutânea destes animais é influenciada por fatores como espécie hospedeira, estágio de vida do hospedeiro, comunidades bacterianas do meio externo e agentes bióticos externos, além das condições ambientais (REBOLLAR et al., 2019).

A pele dos anfíbios é complexa, envolvendo secreções mucosas da pele, peptídeos antimicrobianos produzidos pelo hospedeiro, microrganismos e metabólitos produzidos microbialmente. Enquanto ambos os fatores de simbiose e do hospedeiro são importantes na determinação da composição da microbiota, o hospedeiro anfíbio provavelmente tem uma forte influência na composição dos microrganismos que habitam a pele (WALKE et al., 2014). Assim como já foi citado anteriormente, muitas dessas bactérias que habitam a pele dos anfíbios agem como organismos simbiontes, e de certa forma fazem parte do sistema imune inato do animal, protegendo os mesmos contra infecções por outros microrganismos patogênicos.

O padrão de grupos bacterianos encontrados segue os relatados por outros autores, que incluem Pseudomonadaceae e Enterobacteriaceae (BELDEN et al., 2015; REBOLLAR et al., 2016). 
Os gêneros bacterianos encontrados neste estudo apresentam bactérias patogênicas e não patogênicas, o que pode ser comum em anfíbios clinicamente normais, e a patogenicidade dessas bactérias se torna possível quando o número de patógenos aumenta além do limite pela qual o hospedeiro pode compensar ou quando o mesmo apresenta sistema imunológico comprometido. As causas para um anfíbio desenvolver a doença são complexas, mas provavelmente incluem a interação de componentes antropogênicos e naturais (RONDA et al., 2006; MILLER et al., 2009).

Algumas espécies de anfíbios são adaptadas a vida em habitats urbanos, convivendo nos mesmos lugares que seres humanos, e há ainda anfíbios criados como pets. Embora diversas bactérias potencialmente zoonóticas tenham sido identificadas em anfíbios, a escassez de estudos sobre transmissão comprovada para seres humanos significa que a maioria das zoonoses bacterianas contraídas de anfíbios representam casos raros, com uma baixa carga geral de doenças para os seres humanos (PASMANS et al., 2017).

Dessa forma, enfatiza-se a importância de estudar a microbiota cutânea dos anfíbios, pois além de atualmente estes animais estarem passando por pressão, alguns estando em vias de extinção, por vários fatores já mencionados, há organismos patogênicos que estão acelerando esse processo. Logo, tomar conhecimento dos microrganismos que fazem parte da microbiota destes animais pode ser um passo essencial para frear a iminente extinção de espécies, e trazer novas alternativas para a indústria biotecnológica.

\section{CONCLUSÕES}

Ainda que alguns gêneros de bactérias identificadas nesse estudo possuam espécies que sejam caracterizadas como potenciais agentes patogênicos, não foram encontrados indícios de que estariam causando danos aos animais estudados. Desse modo, é importante que novos estudos sejam realizados com o objetivo de sublimar e inspecionar a microbiota de anfíbios, bem como de prospectar substâncias potencialmente biotecnológicas em benefício do homem e dos animais.

Ademais, é importante que estes estudos visem estudar as relações entre os microrganismos em anfíbios não apenas na pele, mas nos diversos compartimentos onde possam estar se albergando.

AGRADECIMENTOS: Os agradecimentos à Universidade Federal do Oeste do Pará que possibilitou a concessão de bolsa Pro-TCC, que foi de grande ajuda a realização do trabalho. À equipe técnica e de alunos do Laboratório Multidisciplinar de Ensino de Biologia Aplicada e Laboratório de Bacteriologia da UFOPA.

\section{REFERÊNCIAS}

ABARCA, J. G.; ZUNIGA, I.; ORTIZ-MORALES, G.; LUGO, A.; VIQUEZ-CERVILLA, M.; RODRIGUEZ-HERNANDEZ, N.; VÁZQUEZ-SÁNCHEZ, F.; MURILLO-CRUZ, C.; TORRES-RIVERA, E. A.; PINTO-TÓMAZ, A.; GODOY-VITORINO, F.. Characterization of the skin microbiota of the cane toad Rhinella cf. marina in Puerto Rico and Costa Rica. Frontiers in Microbiology, Lausanne, v.8, n.2624, p.1-13, 2018. DOI: https://doi.org/10.3389/fmicb.2017.02624
ACKERMAN, L. J.; KISHIMOTO, R. A.; EMERSON, J. S.. Nonpigmented Serratia marcescens arthritis in a Teju (Tupinambis tequixin). American Journal of Veterinary Research, Schaumburg, v.32, n.5, p.823-826, 1971.

AGUDELO, A. N.; MARTÍNEZ, G. R.; BERNAL, L. A.. Identificación de Mycobacterium sp., en una población de tortugas morrocoy (Geochelone carbonaria) en cautiverio y en su entorno, en un zoológico en la Sabana de Bogotá. 
Revista de Medicina Veterinaria, v.15, p.21-38, 2008. DOI: https://doi.org/10.19052/mv.1452

ALIBI, S.; FERJANI, A.; BOUKADIDA, J.; CANO, M. E.; FERNÁNDEZ-MARTÍNEZ, M.; MARTÍNEZ-MARTÍNEZ, L.; NAVAS, J.. Occurrence of Corynebacterium striatum as an emerging antibiotic-resistant nosocomial pathogen in a Tunisian hospital. Scientific Reports, v.7, n.1, p.1-8, 2017. DOI: https://doi.org/10.1038/s41598-017-10081-y

ANTWIS, R. E.; HAWORTH, R. L.; ENGELMOER, D. J. P.; OGILV, V.; FIDGETT, A. L.; PREZIOSI, R. F.. Ex situ diet influences the bacterial community associated with the skin of red-eyed tree frogs (Agalychnis callidryas). PLoS One, San Francisco, v.9, n.1, e85563, p.1-9, 2014. DOI:

https://doi.org/10.1371/journal.pone.0085563

ANTWIS, R. E.; PREZIOSI, R. F.; HARRISON, X. A.; GARNER, T. W.. Amphibian symbiotic bacteria do not show a universal ability to inhibit growth of the global panzootic lineage of Batrachochytrium dendrobatidis. Applied and Environmental Microbiology, v.81, n.11, p.3706-3711, 2015. DOI: https://doi.org/10.1128/AEM.00010-15

ARAÚJO, M. B.; THUILLER, W.; PEARSON, R. G.. Climate warming and the decline of amphibians and reptiles in Europe. Journal of Biogeography, v.33, p.1712-1728, 2006. DOI: https://doi.org/10.1111/j.1365-2699.2006.01482.x

ARAÚJO, C. L.; ALVES, J.; LIMA, A.; DIAS, L.; SILVA, P.; MARQUES, J.; AZEVEDO, V.; SILVA, A.; FOLADOR, A.. The Genus Corynebacterium in the Genomic Era. In: ENANY, S. Basic Biology and Applications of Actinobacteria. IntechOpen, 2018. p.59-77. DOI: https://doi.org/10.5772/intechopen.72033

ASSIS, A. B.. Microbiota cutânea e secreções dérmicas de Proceratophrys boiei (Amphibia, Anura) em fragmentos de floresta atlântica. Tese (Doutorado em Ciências, Fisiologia Geral) - Universidade de São Paulo, São Paulo, 2015.

BANAS, J. A.; LOESCHE, W. J.; NACE, G. W.. Classification and distribution of large intestinal bacteria in nonhibernating and hibernating leopard frogs (Rana pipiens). Applied and Environmental Microbiology, v.54, n.9, p.2305-2310, 1988.

BECKER, C. G; ZAMUDIO, K. R.. Tropical amphibian populations experience higher disease risk in natural habitats. Proceedings of the National Academy of Sciences, Washington, v.108, n.21, p.9893-9898, 2011. DOI: https://doi.org/10.1073/pnas.1014497108

BECKER, M. H.; WALKE, J. B.; MURRILL, L.; WOODHAMS, D. C.; REINERT, L. K.; ROLLINS-SMITH, L. A.; BURZYNSKI, E. A.; UMILE, T. P.; MINBIOLE, K. P. C.; BELDEN, L. K.. Phylogenetic distribution of symbiotic bacteria from Panamanian amphibians that inhibit growth of the lethal fungal pathogen Batrachochytrium dendrobatidis. Molecular Ecology, v.24, n.7, p.1628-1641, 2015. DOI:

https://doi.org/10.1111/mec.13135

BELDEN, L. K.; HARRIS, R. N.. Infectious diseases in wildlife: the community ecology context. Frontiers in Ecology and the Environment, Washington, v.5, n.10, p.533-539, 2007. DOI: https://doi.org/10.1890/060122

BELDEN, L. K.; HUGHEY, M. C.; REBOLLAR, E. A.; UMMILE, T.
P.; LOFTUS, S. C.; BURZYNSKI, E. A.; MINBIOLE, K. P. C.; HOUSE, L. L.; JENSEN, R. V.; BECKER, M. H.; WALKE, J. B.; MEDINA, D.; IBÁÑEZ, R.; HARRIS, R. N.. Panamanian frog species host unique skin bacterial communities. Frontiers in Microbiology, Lausanne, v.6, n.1171, p.1-21, 2015. DOI: https://doi.org/10.3389/fmicb.2015.01171

BERGER, L.; ROBERTS, A. A.; VOYLES, J.; LONGCORE, J. E.; MURRAY, K. A.; SKERRATT, L. F.. History and recent progress on chytridiomycosis in amphibians. Fungal Ecology, v.19, p.89-99, 2016. DOI:

https://doi.org/10.1016/i.funeco.2015.09.007

BERGEY, D. H.; HOLT, J. G.. Bergey's Manual of Determinative Bacteriology. Philadelphia: Lippincott Williams \& Wilkins, 2000.

BIBERSTEIN, E. L.; HIRSH, D. C.. Estreptococos. In: HIRSH, D. C.; ZEE, Y. C.. Microbiologia Veterinária. Rio de Janeiro: Guanabara Koogan, 2012a. p.113-118.

BIBERSTEIN, E. L.; HIRSH, D. C.. O Gênero Bacillus. In: HIRSH, D. C.; ZEE, Y. C.. Microbiologia Veterinária. Rio de Janeiro: Guanabara Koogan, 2012b. p.231-234.

BIBERSTEIN, E. L.; HIRSH, D. C.. Os Clostrídios. In: HIRSH, D. C.; ZEE, Y. C.. Microbiologia Veterinária. Rio de Janeiro: Guanabara Koogan, 2012c. p.219-230.

BLETZ, M. C.; PERL, R. G. B.; VENCES, M.. Skin microbiota differs drastically between co-occurring frogs and newts. Royal Society Open Science, London, v.4, n.170107, p.1-15, 2017. DOI: https://doi.org/10.1098/rsos.170107

BOAM, G. W.; SANGER, V. L.; COWAN, D. F.; VAUGHAN, D. $P$.. Subcutaneous abscesses in iguanid lizards. Journal of the American Veterinary Medical Association, Schaumburg, v.157, n.5, p.617-619, 1970.

BOS, J. D.; LUITEN, R. M.. Skin Immune System. In: STOCKFLETH, E.; ULRICH, C.. Skin Cancer after Organ Transplantation. Washington: Springer, 2009. p.45-62. DOI: https://doi.org/10.1007/978-0-387-78574-5

BRESCIANO, J. C.; SALVADOR, C. A.; PAZ-Y-MINO, C.; PARODY-MERINO, A. M.; BOSCH, J.; WOODHAMS, D. C. Variation in the presence of anti-Batrachochytrium dendrobatidis bacteria of amphibians across life stages and elevations in Ecuador. EcoHealth, v.12, n.2, p.310-319, 2015. DOI: https://doi.org/10.1007/s10393-015-1010-y

CAMPBELL, A.. Declines and disappearances of Australian frogs. Canberra: Environment Australia, 1999.

CARVALHO, T.; BECKER, C. G.; TOLEDO, L. F.. Historical amphibian declines and extinctions in Brazil linked to chytridiomycosis. Proceedings of the Royal Society B: Biological Sciences, London, v.284, n.1848, 2017. DOI: https://doi.org/10.1098/rspb.2016.2254

CASAS, I. A.; DOBROGOSZ, W. J.. Validation of the probiotic concept: Lactobacillus reuteri confers broad-spectrum protection against disease in humans and animals. Microbial Ecology in Health and Disease, v.12, n.4, p.247-285, 2000. DOI: https://doi.org/10.1080/08910600050216246-1

CATENAZZI, A.. State of the world's amphibians. Annual 
Review of Environment and Resources, Palo Alto, v.40, p.91-119, 2015. DOI: https://doi.org/10.1146/annurevenviron-102014-021358

CHAl, N.. Mycobacteriosis in amphibians. In: MILLER, R. E.; FOWLER, M.. Fowler's Zoo and Wild Animal Medicine Current Therapy. Saunders, 2011. p.224-230.

CLAUSEN, H. J.; DURAN-REYNALS, F.. Studies on the experimental infection of some reptiles, amphibia and fish with Serratia anolium. The American Journal of Pathology, Philadelphia, v.13, n.3, p.441-453, 1937.

COLOMBO, B. M.; SCALVENZI, T.; BENLAMARA, S.; POLLET, N.. Microbiota and mucosal immunity in amphibians. Frontiers in Immunology, Lausanne, v.6, n.111, p.1-15, 2015. DOI: https://doi.org/10.3389/fimmu.2015.00111

COLWELL, R. R.; CHUN, J.. The Genus Vibrio and Related Genera. In: GOLDMAN, E.; GREEN, L. H.. Practical Handbook of Microbiology. Washington: CRC Press Taylor \& Francis Group, 2008. p.267-273. DOI:

https://doi.org/10.1201/9781420009330

CORTI, M. A. M.; BLOEMBERG, G. V.; BORELLI, S.; KUTZNER, H.; EICH, G.; HOELZLE, L.; LAUTENSCHLAGER, S.. Rare human skin infection with Corynebacterium ulcerans: transmission by a domestic cat. Infection, v.40, n.5, p.575-578, 2012. DOI: https://doi.org/10.1007/s15010-012-0254-5

CULP, C. E.; FALKINHAM III, J. O.; BELDEN, L. K.. Identification of the natural bacterial microflora on the skin of eastern newts, bullfrog tadpoles and redback salamanders. Herpetologica, Washington, v.63, n.1, p.66-71, 2007. DOI: https://doi.org/10.1655/00180831(2007)63[66:IOTNBM]2.0.CO;2

DEL-POZO, J.; GIRLING, S.; PIZZI, R.; MANCINELLI, E.; ELSE, R. W.. Severe necrotizing myocarditis caused by Serratia marcescens infection in an axolotl (Ambystoma mexicanum). Journal of Comparative Pathology, v.144, n.4, p.334-338, 2011. DOI: https://doi.org/10.1016/i.jcpa.2010.11.001

DIAS, A. A. S. O.; SANTOS, L. S.; SABBADINI, P. S.; SANTOS, C. S.; SILVA JUNIOR, F. C.; NAPOLEÃO, F.; NAGAO, P. E.; VILLASBÔAS, M. H. S.; HIRATA JUNIOR, R.; GUARALDI, A. L. M.. Corynebacterium ulcerans diphtheria: an emerging zoonosis in Brazil and worldwide. Revista de Saúde Pública, São Paulo, v.45, n.6, p.1176-1191, 2011. DOI: https://doi.org/10.1590/s0034-89102011000600021

DOUGLAS, S. I.; AMUZIE, C. C.. Microbiological quality of Hoplobatrachus occipitalis (Amphibia, Anura) used as meat. International Journal of Current Microbiology and Applied Sciences, Tamilnadu, v.6, n.6, p.3192-3200, 2017. DOI: https://doi.org/10.20546/ijcmas.2017.606.376

DUCATI, R. G.; LEÃO, S. C.; BASSO, L. A.; SANTOS, D. S.. Micobactérias. In: TRABULSI, L.R.; ALTERTHUM, F.. Microbiologia. São Paulo: Atheneu, 2015. p.481-498.

DURAN-REYNALS, F.; CLAUSEN, H. J.. A contagious tumorlike condition in the lizard (Anolis equestris) as induced by a new bacterial species, Serratia anolium (sp. n.). Journal of Bacteriology, v.33, n.4, p.369-379, 1937.
DÜRRE, P.. The Genus Clostridium. In: GOLDMAN, E.; GREEN, L. H.. Practical Handbook of Microbiology. Washington: CRC Press Taylor \& Francis Group, 2008. p.339-353. DOI: https://doi.org/10.1201/9781420009330

EBRAHIMIPOUR, G. H.; KHOSRAVIBABADI, Z.; SADEGHI, H.; ALIAHMADI, A.. Isolation, Partial Purification and Characterization of an Antimicrobial Compound, Produced by Bacillus atrophaeus. Jundishapur Journal of Microbiology, Ahvaz, v.7, n.9, p.11802, 2014. DOI: https://dx.doi.org/10.5812/jim.11802

EGGELING, L.; BOTT, M.. The Genus Corynebacterium. In: GOLDMAN, E.; GREEN, L. H.. Practical Handbook of Microbiology. Washington: CRC Press Taylor \& Francis Group, 2008. p.355-374. DOI: https://doi.org/10.1201/9781420009330

ETEROVICK, P. C.; CARNAVAL, A. C. O. Q.; BORGES-NOJOSA, D. M.; SILVANO, D. L.; SEGALLA, M. V.; SAZIMA, I.. Amphibian declines in Brazil: an overview. Biotropica, v.37, n.2, p.166179, 2005. DOI: https://doi.org/10.1111/i.17447429.2005.00024.x

FERREIRA, M. C. S.; DOMINGUES, R. M. C. P.; LOBO, L. A.; FERREIRA, E. O.. Clostridium. In: TRABULSI, L. R.; ALTERTHUM, F.. Microbiologia. São Paulo: Atheneu, 2015. p.449-456.

FISCHETTI, V. A.; RYAN, P.. The Genus Streptococcus. In: GOLDMAN, E.; GREEN, L. H.. Practical Handbook of Microbiology. United States of America: CRC Press Taylor \& Francis Group, 2008. p.295-307. DOI: https://doi.org/10.1201/9781420009330

FROST, D. R.. Amphibian Species of the World: An Online Reference. Version 6.1 Electronic Database accessible. New York: American Museum of Natural History, 2020. DOI: https://doi.org/10.5531/db.vz.0001

GOLEMI-KOTRA, D.. Pseudomonas Infections. In: ENNA, S. J.; BYLUND, D. B.. xPharm: The Comprehensive Pharmacology Reference. Boston: Elsevier, 2008. p.1-8.

GREEN, D. E.; CONVERSE, K. A.; SCHRADER, A. K.. Epizootiology of sixty-four amphibian morbidity and mortality events in the USA, 1996-2001. Annals of the New York Academy of Sciences, v.969, n.1, p.323-339, 2002. DOI: https://doi.org/10.1111/i.1749-6632.2002.tb04400.x

GRIMONT, F.; GRIMONT, P. A. D.. The Genus Serratia. In: DWORKIN, D.; FALKOW, S.; ROSENBERG, E.; SCHLEIFER, K.H.; STACKEBRANDT, E.. The Prokaryotes: A Handbook on the Biology of Bacteria. New York: Springer, 2006. p.219-244. DOI: https://doi.org/10.1007/978-1-4757-2191-1

HACIOGLU, N.; TOSUNOGLU, M.. Determination of antimicrobial and heavy metal resistance profiles of some bacteria isolated from aquatic amphibian and reptile species. Environmental Monitoring and Assessment, v.186, n.1, p.407-413, 2014. DOI: https://doi.org/10.1007/s10661$\underline{013-3385-y}$

HAMANN, M. I.; GONZÁLEZ, C. E.. Helminth parasites in the toad Rhinella major (Bufonidae) from Chaco region, Argentina. Acta Herpetologica, Washington, v.10, n.2, p.93101, 2015. DOI: http://dx.doi.org/10.13128/Acta Herpetol- 
$\underline{16150}$

HEYNOL, V.; HECKERS, K. O.; BEHNCKE, H.; HEUSINGER, A.; MARSCHANG, R. E.. Detection of bacteria in oral swabs from healthy common musk turtles (Sternotherus odoratus) and West African mud turtles (Pelusios castaneus). Journal of Herpetological Medicine and Surgery, Washington, v.25, n.1-2, p.33-39, 2015. DOI: https://doi.org/10.5818/1529$\underline{9651-25.1 .33}$

HIRATA JÚNIOR, R.; MATTOS-GUARALDI, A. L.. Corynebacterium diphtheriae e Outras Espécies do Gênero. In: TRABULSI, L. R.; ALTERTHUM, F.. Microbiologia. São Paulo: Atheneu, 2015. p.245-254.

HIRSH, D. C.. Escherichia. In: HIRSH, D. C.; ZEE, Y. C.. Microbiologia Veterinária. Rio de Janeiro: Guanabara Koogan, 2012. p.63-68.

HUGHEY, M. C.; PENA, J. A.; REYES, R.; MEDINA, D.; BELDEN, L. K.; BURROWES, P. A.. Skin bacterial microbiome of a generalist Puerto Rican frog varies along elevation and land use gradients. PeerJ, San Diego, v.5, n.e3688, 2017. DOI: https://doi.org/10.7717/peerj.3688

IGLEWSKI, B. H.. Pseudomonas. In: BARON S.. Medical Microbiology. Galveston: University of Texas Medical Branch, 1996.

JACKSON, C. G. JR.; FULTON, M.. A turtle colony epizootic apparently of microbial origin. Journal of Wildlife Disease, Lawrence, v.6, n.4, p.466-468, 1976. DOI:

https://doi.org/10.7589/0090-3558-6.4.466

JANDA, J. M.; ABBOTT, S. L.. The Family Enterobacteriaceae. In: GOLDMAN, E.; GREEN, L. H.. Practical Handbook of Microbiology. Washington: CRC Press Taylor \& Francis Group, 2008. p.217-230. DOI:

https://doi.org/10.1201/9781420009330

KLAPHAKE, E.. Bacterial and parasitic diseases of amphibians. Veterinary Clinics: Exotic Animal Practice, v.12, n.3, p.597-608, 2009. DOI:

https://doi.org/10.1016/i.cvex.2009.06.005

KOHL, K. D.; YAHN, J.. Effects of environmental temperature on the gut microbial communities of

tadpoles. Environmental Microbiology, v.18, n.5, p.15611565, 2016. DOI: https://doi.org/10.1111/1462-2920.13255

LABOMBARDI, V. J.. The Genus Mycobacteria. In: GOLDMAN, E.; GREEN, L. H.. Practical Handbook of Microbiology. United States of America: CRC Press Taylor \& Francis Group, 2008. p. 493-504. DOI:

https://doi.org/10.1201/9781420009330

LAM, B. A.; WALKE, J. B.; VREDENBURG, V. T.; HARRIS, R. N.. Proportion of individuals with anti-Batrachochytrium dendrobatidis skin bacteria is associated with population persistence in the frog Rana muscosa. Biological Conservation, v.143, p.529-531, 2010. DOI: https://doi.org/10.1016/j.biocon.2009.11.015

LEITÃO, N. M. D. A.; PINHEIRO, A. K. B.; ANJOS, S. D. J. S. B.; VASCONCELOS, C. T. M.; NOBRE, R. N. S.. Avaliação dos laudos citopatológicos de mulheres atendidas em um serviço de enfermagem ginecológica. Revista Mineira de
Enfermagem, Belo Horizonte, v.12, n.4, p.508-515, 2008.

LOKMER, A.; WEGNER, K. M.. Hemolymph microbiome of Pacific oysters in response to temperature, temperature stress and infection. The ISME Journal, Wageningen, v.9, n.3, p.670-682, 2015. DOI:

https://dx.doi.org/10.1038\%2Fismej.2014.160

LOUDON, A. H.; HOLLAND, J. A.; UMILE, T. P.; BURZYNSKI, E. A.; MINBIOLE, K. P.; HARRIS, R. N.. Interactions between amphibians' symbiotic bacteria cause the production of emergent anti-fungal metabolites. Frontiers in Microbiology, Lausanne, v.5, n.441, p.1-7, 2014. DOI: https://doi.org/10.3389/fmicb.2014.00441

MADISON, J. D.; BERG, E. A.; ABARCA, J. G.; WHITFIELD, S. M.; GORBATENKO, O.; PINTO, A.; KERBY, J. L..

Characterization of Batrachochytrium dendrobatidis inhibiting bacteria from amphibian populations in Costa

Rica. Frontiers in Microbiology, Lausanne, v.8, n.290, p.1-13, 2017. DOI: https://doi.org/10.3389/fmicb.2017.00290

MARIN, M. A.; MORAIS, L. L. C. S.; VICENTE, A. C. P.. Vibrio cholerae e Outros Vibrios de Importância Médica. In: TRABULSI, L. R.; ALTERTHUM, F.. Microbiologia. São Paulo: Atheneu, 2015. p.375-382.

MASTROMARINO, P.; VITALI, B.; MOSCA, L.. Bacterial vaginosis: a review on clinical trials with probiotics. New Microbiologica, Bologna, v.36, n.3, p.229-238, 2013.

MCFALL-NGAI, M.; HADFIELD, M. G.; BOSCH, T. C.; CAREY, H. V.; DOMAZET-LOŠO, T.; DOUGLAS, A. E.; DUBILIER, N.; EBERL, G.; FUKAMI, T.; GILBERT, S. F.; HENTSCHEL, U.; KING, N.; KJELLEBERG, S.; KNOLL, A. H.; KREMER, N.; MAZMANIAN, S. K.; METCALF, J. L.; NEALSON, K.; PIERCE, N. E.; RAWLS, J. F.; REID, A.; RUBY, E. G.; RUMPHO, M.; SANDERS, J. G.; TAUTZ, D.; WERNEGREEN, J.. Animals in a bacterial world, a new imperative for the life sciences. Proceedings of the National Academy of Sciences, Washington, v.110, n.9, p.3229-3236, 2013. DOI: https://doi.org/10.1073/pnas.1218525110

MENDOZA, G. M.; PASTERIS, S. E.; ALE, C. E.; OTERO, M. C.; BÜHLER, M. I.; NADER-MACÍAS, M. E. F.. Cultivable microbiota of Lithobates catesbeianus and advances in the selection of lactic acid bacteria as biological control agents in raniculture. Research in Veterinary Science, v.93, n.3, p.1160-1167, 2012. DOI: https://doi.org/10.1016/i.rvsc.2012.05.007

MILLER, D. L.; GRAY, M. J.; RAJEEV, S.; SCHMUTZER, A. C.; BURTON, E. C.; MERRILL, A.; BALDWIN, C. A.. Pathologic findings in larval and juvenile anurans inhabiting farm ponds in Tennessee, USA. Journal of Wildlife Diseases, Lawrence, v.45, n.2, p.314-324, 2009. DOI: https://doi.org/10.7589/0090-3558-45.2.314

MITCHELL, K. M.; CHURCHER, T. S.; GARNER, T. W. J.; FISHER, M. C.. Persistence of the emerging pathogen

Batrachochytrium dendrobatidis outside the amphibian host greatly increases the probability of host extinction.

Proceedings of the Royal Society B: Biological Sciences, London, v.275, p.329-334, 2007. DOI:

https://doi.org/10.1098/rspb.2007.1356

NARVAES, P.; RODRIGUES, M. T.. Taxonomic revision of 
Rhinella granulosa species group (Amphibia, Anura, Bufonidae), with a description of a new species. Arquivos de Zoologia, São Paulo, v.40, n.1, p.1-73, 2009. DOI: https://doi.org/10.11606/issn.2176-7793.v40i1p1-73

NESS, R. B.; HILLIER, S. L.; RICHTER, H. E.; SOPER, D. E.; STAMM, C.; MCGREGOR, J.; BASS, D. C.; SWEET, R. L.; RICE, P.. Douching in relation to bacterial vaginosis, lactobacilli, and facultative bacteria in the vagina. Obstetrics \& Gynecology, v.100, n.4, p.765-772, 2002. DOI: https://doi.org/10.1016/s0029-7844(02)02184-1

NIEDERLE, M. V.; BOSCH, J.; ALE, C. E.; NADER-MACÍAS, M. E.; FICOSECO, C. A.; TOLEDO, L. F.; VALENZUELA-SÁNCHEZ, A.; SOTO-AZAT, C.; PASTERIS, S. E.. Skin-associated lactic acid bacteria from North American bullfrogs as potential control agents of Batrachochytrium dendrobatidis. Plos One, San Francisco, v.14, n.9, p.1-23, 2019. DOI: https://dx.doi.org/10.1371\%2Fjournal.pone.0223020

NOLASCO, L.. Caracterização da microbiota cutânea de Brachycephalus ephippium e Aplastodiscus leucopygius do Parque Natural Municipal Augusto Ruschi. Monografia (Bacharelado em Ciências Biológicas) - Universidade do Vale do Paraíba, São José dos Campos, 2016.

NOWAKIEWICZ, A.; ZIÓŁKOWSKA, G.; ZIĘBA, P.; DZIEDZIC, B. M.; GNAT, S.; WÓJCIK, M.; DZIEDZIC, R.; KOSTRUBA, A.. Aerobic bacterial microbiota isolated from the cloaca of the European pond turtle (Emys orbicularis) in Poland. Journal of Wildlife Diseases, Lawrence, v.51, n.1, p.255-259, 2015. DOI: https://doi.org/10.7589/2013-07-157

O'ROURKE, D. P.; ROSENBAUM, M. D.. Biology and diseases of amphibians. In: ANDERSON, L.; OTTO, G.; PRITCHETTCORNING, K.; WHARY, M.. Laboratory Animal Medicine. Academic Press, 2015. p.931-965.

OLIVEIRA, A.; OLIVEIRA, L. C.; ABURJAILE, F.; BENEVIDES, L.; TIWARI, S.; JAMAL, S. B.; SILVA, A.; FIGUEIREDO, H. C. P.; GHOSH, P.; PORTELA, R. W.; DE CARVALHO AZEVEDO, V. A.; WATTAM, A. R.. Insight of genus Corynebacterium: ascertaining the role of pathogenic and non-pathogenic species. Frontiers in Microbiology, Lausanne, v.8, n.1937, p.1-18, 2017. DOI:

https://doi.org/10.3389/fmicb.2017.01937

ÖZEN, A. I.; USSERY, D. W.. Defining the Pseudomonas Genus: Where Do We Draw the Line with Azotobacter?. Microbial Ecology, v.63, n.2, p.239-248, 2012. DOI: https://doi.org/10.1007/s00248-011-9914-8

PANTOSTI, A.. Methicillin-resistant Staphylococcus aureus associated with animals and its relevance to human health. Frontiers in Microbiology, Lausanne, v.3, n.127, p.1-12, 2012. DOI: https://doi.org/10.3389/fmicb.2012.00127

PASMANS, F.; BOGAERTS, S.; CUNNINGHAM, A. A.; BRAECKMAN, J.; HELLEBUYCK, T.; GRIFFITHS, R. A.; SPARREBOOM, M.; SCHMIDT, B. R.; MARTEL, A.. Future of keeping pet reptiles and amphibians: towards integrating animal welfare, human health and environmental sustainability. Veterinary Record, London, v.181, n.7, p.1-30, 2017. DOI: https://doi.org/10.1136/vr.104296

PASTERIS, S. E.; BÜHLER, M. I.; NADER-MACÍAS, M. E. Microbiological and histological studies of farmed-bullfrog
(Rana catesbeiana) tissues displaying red-leg syndrome.

Aquaculture, v.251, n.1, p.11-18, 2006. DOI:

https://doi.org/10.1016/i.aquaculture.2005.05.007

PASTERIS, S. E.; PINGITORE, E. V.; BABOT, G. R.; OTERO, M. C.; BÜHLER, M. I.; NADER-MACÍAS, M. E.. Characterization of the beneficial properties of lactobacilli isolated from bullfrog (Rana catesbeiana) hatchery. Antonie Van Leeuwenhoek, v.95, n.4, p.373-385, 2009. DOI:

https://doi.org/10.1007/s10482-009-9329-4

PEIX, A.; RAMÍREZ-BAHENA, M.; VELÁZQUEZ, E.. Historical evolution and current status of the taxonomy of genus Pseudomonas. Infection, Genetics and Evolution, v.9, n.6, p.1132-1147, 2009. DOI:

https://doi.org/10.1016/j.meegid.2009.08.001

PELOSO, P. L. V.; MACHADO, I.; BECKER, G.. Fotografia da conservação na herpetologia: um ensaio sobre anfíbios ameaçados de extinção no Brasil. Herpetologia Brasileira, v.8, n.1, p.26-29, 2019.

PEREIRA, H. C.; GOMES, D. O.; HIRANO, L. Q. L.; SANTOS, A. L. Q.; LIMA, A. M. C.. Oral microbiota in healthy Bothrops atrox (Serpentes: Viperidae) and in snakes with stomatitis. Acta Veterinaria Brasílica, Mossoró, v.11, n.3, p.180-183, 2017. DOI: https://doi.org/10.21708/avb.2017.11.0.7157

PILARSKI, F.; SCHOCKEN-ITURRINO, R. P.. Isolamento e resistência a antimicrobianos de cepas de Streptococcus spp. provenientes de rãs-touro (Lithobates catesbeianus). Arquivo Brasileiro de Medicina Veterinária e Zootecnia, São Paulo, v.62, n.5, p.1275-1279, 2010. DOI: http://dx.doi.org/10.1590/S0102-09352010000500036

PINHEIRO, M. D. F. D. S.. Staphylococcus aureus em 2 (duas) rãs-touro (Rana catesbeiana) de um ranário em Belém, PA. Acta Amazônica, Manaus, v.19, p.343-348, 1989. DOI: https://doi.org/10.1590/1809-43921989191348

PIOVIA-SCOTT, J.; REJMANEK, D.; WOODHAMS, D. C.; WORTH, S. J.; KENNY, H.; MCKENZIE, V.; LAWLER, S. P.; FOLEY, J. E.. Greater species richness of bacterial skin symbionts better suppresses the amphibian fungal pathogen Batrachochytrium dendrobatidis. Microbial Ecology, v.74, n.1, p.217-226, 2017. DOI: https://doi.org/10.1007/s00248016-0916-4

POUGH, F. H.; JANIS, C. M.; HEISER, J. B.. A Vida dos Vertebrados. 4 ed. São Paulo: Atheneu, 2008.

PRIEST, F. G.. Bacillus. In: REHM, H.-J.; REED, G. Biotechnology: Biological Fundamentals. Wiley VCH, 1993. p.367-400.

PUKALA, T. L.; BOWIE, J. H.; MASELLI, V. M.; MUSGRAVE, I. F.; TYLER, M. J.. Host-defence peptides from the glandular secretions of amphibians: structure and activity. Natural Product Reports, v.23, n.3, p.368-393, 2006. DOI: https://doi.org/10.1039/b512118n

REBOLLAR, E. A.; HUGHEY, M. C.; MEDINA, D.; HARRIS, R. N.; IBÁÑEZ, R.; BELDEN, L. K.. Skin bacterial diversity of Panamanian frogs is associated with host susceptibility and presence of Batrachochytrium dendrobatidis. The ISME Journal, Wageningen, v.10, p.1682-1695, 2016. DOI: 
https://doi.org/10.1038/ismej.2015.234

REBOLLAR, E. A.; HARRIS, R. N.. Ecology of AmphibianMicrobial Symbioses. Frontiers in Microbiology, Lausanne, v.10, n.766, p.1-3, 2019. DOI:

https://doi.org/10.3389/fmicb.2019.00766

ROMERO, R. A. M.. Infecções por Ranavirus e cocos grampositivos em girinos e rãs de criação (Rana catesbeiana Shaw, 1802) do estado de Goiás. Tese (Doutorado em Ciência Animal) - Universidade Federal de Goiás, Goiânia, 2006.

RONDA, J. G.; SAUMELL, F. B.; MARTÍNEZ-SILVESTRE, A.. LaS enfermedades de los anfibios. Auxiliar Veterinario, v.3, p.38-43, 2006.

RÖNNQVIST, P. D. J.; FORSGREN-BRUSK, U. B.; GRAHNHÅKANSSON, E. E.. Lactobacilli in the female genital tract in relation to other genital microbes and vaginal $\mathrm{pH}$. Acta Obstetricia et Gynecologica Scandinavica, v.85, n.6, p.726735, 2006. DOI:

https://doi.org/10.1080/00016340600578357

ROSENBERG, E.; KOREN, O.; RESHEF, L.; EFRONY, R.; ZILBERROSENBERG, I.. The role of microorganisms in coral health, disease and evolution. Nature Reviews Microbiology, v.5, n.5, p.355-362, 2007. DOI:

https://doi.org/10.1038/nrmicro1635

ROSS, A. A.; HOFFMANN, A. R.; NEUFELD, J. D.. The skin microbiome of vertebrates. Microbiome, v.7, n.79, p.1-14, 2019. DOI: https://doi.org/10.1186/s40168-019-0694-6

SABINO-PINTO, J.; BLETZ, M. C.; ISLAM, M. M.; SHIMIZU, N.; BHUJU, S.; GEFFERS, R.; JAREK, M.; KURABAYASHI, A.; VENCES, M.. Composition of the cutaneous bacterial community in Japanese amphibians: effects of captivity, host species, and body region. Microbial Ecology, v.72, n.2, p.460-469, 2016. DOI: https://doi.org/10.1007/s00248-016$\underline{0797-6}$

SANTOS, C.. Caracterização da microbiota presente na pele do anuro Phyllomedusa distincta pela análise da biblioteca do gene do RNAr 16S. Monografia (Bacharelado em Farmácia) - Universidade Católica de Brasília, Brasília, 2013.

SCHEELE, B. C.; PASMANS F.; SKERRATT, L. F; BERGER, L.; MARTEL, A.; BEUKEMA, W.; ACEVEDO, A. A.; BURROWES, P. A.; CARVALHO, T.; CATENAZZI, A.; DE LA RIVA, I.; FISHER, M. C.; FLECHAS, S. V.; FOSTER, C. N.; FRÍAS-ÁLVAREZ, P.; GARNER, T. W. J.; GRATWICKE, B.; GUAYASAMIN, J. M.; HIRSCHFELD, M.; KOLBY, J. E.; KOSCH, T. A.; LA MARCA, E.; LINDENMAYER, D. B.; LIPS, K. R.; LONGO, A. V.; MANEYRO, R.; MCDONALD, C. A.; MENDELSON III, J.; PALACIOSRODRIGUEZ, P.; PARRA-OLEA, G.; RICHARDS-ZAWACKI, C. L.; RÖDEL, M-O.; ROVITO, S. M.; SOTO-AZAT, C.; TOLEDO, L. F.; VOYLES, J.; WELDON, C.; WHITFIELD, S. M.; WILKINSON, M.; ZAMUDIO, K. R.; CANESSA S.. Amphibian fungal panzootic causes catastrophic and ongoing loss of biodiversity. Science, v.363, p.1459-1463, 2019. DOI: https://doi.org/10.1126/science.aav0379

SCHIPPER, J.; CHANSON, J. S.; CHIOZZA, F.; COX, N. A.; HOFFMANN, M.; KATARIYA, V.; LAMOREUX, J.; RODRIGUES, A. S. L.; STUART, S. N.; TEMPLE, H. J.; BAILLIE, J.; BOITANI, L.; LACHER, T. E.; MITTERMEIER, R. A.; SMITH, A. T.; ABSOLON,
D.; AGUIAR, J. M.; AMORI, G.; BAKKOUR, N.; BALDI, R.; BERRIDGE, R. J.; BIELBY, J.; BLACK, P. A.; BLANC, J. J.; BROOKS, T. M.; BURTON, J. A.; BUTYNSKI, T. M.; CATULLO, G.; CHAPMAN, R. COKELISS, Z.; COLLEN, B.; CONROY, J.; COOKE, J. G.; DA FONSECA, G. A. B.; DEROCHER, A. E.; DUBLIN, H. T.; DUCKWORTH, J. W.; EMMONS, L.; EMSLIE, R. H.; FESTA-BIANCHET, M.; FOSTER, M.; FOSTER, S.; GARSHELIS, D. L.; GATES, C.; GIMENEZ-DIXON, M.; GONZALEZ, S.; GONZALEZ-MAYA, J. F.; HAMMOND, P. S.; HAPPOLD, D.; HAPPOLD, M.; HARE, J.; HARRIS, R. B.; HAWKINS, C. E.; HAYWOOD, M.; HEANEY, L. R.; HEDGES, S.; HELGEN, K. M.; HILTON-TAYLOR, C.; HUSSAIN, S. A.; ISHII, N.; JEFFERSON, T. A.; JENKINS, R. K. B.; JOHNSTON, C. H.; KEITH, M.; KINGDON, J.; KNOX, D. H.; KOVACS, K. M.;

LANGHAMMER, P.; LEUS, K.; LEWISON, R.; LICHTENSTEIN, G.; LOWRY, L. F.; MACAVOY, Z.; MACE, G. M.; MALLON, D. P.; MASI, M.; MCKNIGHT, M. W.; MEDELLÍN, R. A.; MEDICI, P.; MILLS, G.; MOEHLMAN, P. D.; MOLUR, S.; MORA, A.; NOWELL, K.; OATES, J. F.; OLECH, W.; OLIVER, W. R. L.; OPREA, M.; PATTERSON, B. D.; PERRIN, W. F.; POLIDORO, B. A.; POLLOCK, C.; POWEL, A.; PROTAS, Y.; RACEY, P.; RAGLE, J.; RAMANI, P.; RATHBUN, G.; REEVES, R. R.; REILLY, S. B.; REYNOLDS, J. E.; RONDININI, C.; ROSELL-AMBAL, R. G.; RULLI, M.; RYLANDS, A. B.; SAVINI, S.; SCHANK, C. J.; SECHREST, W.; SELF-SULLIVAN, C.; SHOEMAKER, A.; SILLERO-ZUBIRI, C.; DE SILVA, N.; SMITH, D. E.; SRINIVASULU, C.; STEPHENSON, P. J.; STREIN, N. V.; TALUKDAR, B. K.; TAYLOR, B. L.; TIMMINS, R.; TIRIRA, D. G.; TOGNELLI, M. F.; TSYTSULINA, K.; VEIGA, L. M.; VIÉ, J.-C.; WILLIAMSON, E. A.; WYATT, S. A.; XIE, Y.; YOUNG, $B$. E.. The status of the world's land and marine mammals: diversity, threat, and knowledge. Science, v.322, n.5899, p.225-230, 2008. DOI: https://doi.org/10.1126/science.1165115

SCHNEEWIND, O.; MISSIAKAS, D.. Staphylococcus aureus and Related Staphylococci. In: GOLDMAN, E.; GREEN, L. H..

Practical Handbook of Microbiology. Washington: CRC Press Taylor \& Francis Group, 2008. p.275-294. DOI: https://doi.org/10.1201/9781420009330

SEBBEN, A.. Microdissecação fisiológica a fresco: uma nova visão sobre a anatomia de anfíbios e répteis. In: NASCIMENTO, L. B.; OLIVEIRA, M. E.. Herpetologia no Brasil II. Belo Horizonte: Sociedade Brasileira de Herpetologia, 2007. p.311-325.

SIGIRCI, B. D.; ALABAS, B.; HALAC, B.; YUKSEL, H. T.; IKIZ, S.. An abscess caused by Corynebacterium pseudotuberculosis in a Budgett's frog (Lepidobatrachus laevis): a case report. Journal of Exotic Pet Medicine, v.31, p.57-60, 2019. DOI: https://doi.org/10.1053/j.jepm.2019.06.004

SKERRATT, L. F.; BERGER, L.; SPEARE, R.; CASHINS, S.; MCDONALD, K. R.; PHILLOTT, A. D.; HINES, H. B.; KENYON, N.. Spread of chytridiomycosis has caused the rapid global decline and extinction of frogs. EcoHealth, v.4, p.215-134, 2007. DOI: https://doi.org/10.1007/s10393-007-0093-5

SOPER, D. E.. Gynecologic complications of bacterial vaginosis: fact or fiction?. Current Infectious Disease Reports, v.1, n.4, p.393-397, 1999. DOI: https://doi.org/10.1007/s11908-999-0048-9

TADDEI, C. R.; BRANDT, K.; CARNEIRO-SAMPAIO, M.. Microbiota Humana. In: TRABULSI, L. R.; ALTERTHUM, F.. Microbiologia. São Paulo: Atheneu, 2015. p.101-108. 
TEIXEIRA, L. M.; PINTO, T. C. A.; MERQUIOR, V. L. C. Streptococcus, Enterococcus e Gêneros Relacionados. In: TRABULSI, L. R.; ALTERTHUM, F.. Microbiologia. São Paulo: Atheneu, 2015. p.195-199.

TEUBER, M.. Lactic Acid Bacteria. In: REHM, H. J.; REED, G.. Biotechnology: Biological Fundamentals. Weinheim: Wiley, 1993. p.325-366.

TORTORA, G. J.; FUNKE, B. R.; CASE, C. L.. Microbiologia. 10 ed. Porto Alegre: Artmed, 2008.

TÜMMLER, B.; WIEHLMANN, L. KLOCKGETHER, J.; CRAMER, N.. Advances in understanding Pseudomonas. F1000prime Reports, London, v.6, n.9, p.1-9, 2014. DOI: https://dx.doi.org/10.12703/P6-9

VANDEPLAS, S.. Attempt to develop treatments based on bacteria-enzyme combination to reduce broiler contamination by two main human bacterial food-born enteric pathogens. Tese (Doutorado em Ciências Agronômicas e Engenharia Biológica) - University of Liège, Gembloux, Belgium, 2010.

VARELA, B. J.; LESBARRÈRES, D.; IBÁÑEZ, R.; GREEN, D. M.. Environmental and host effects on skin bacterial community composition in Panamanian frogs. Frontiers in Microbiology, Lausanne, v.9, n.298, p.1-13, 2018. DOI: https://doi.org/10.3389/fmicb.2018.00298

VERDADE, V. K.; VALDUJO, P. H.; CARNAVAL, A. C.; SCHIESARI, L.; TOLEDO, L. F.; MOTT, T.; ANDRADE, G. V.; ETEROVICK, P. C.; MENIN, M.; PIMENTA, B. V. S.; NOGUEIRA, C.; LISBOA, C. S.; DE PAULA, C. D.; SILVANO, D. L.. A leap further: the Brazilian amphibian conservation action plan. Alytes, v.29, n.1-4, p.28-43, 2012.

WAGNER, K. S.; WHITE, J. M.; CROWCROFT, N. S.; DE MARTIN, S.; MANN, G.; EFSTRATIOU, A.. Diphtheria in the United Kingdom, 1986-2008: the increasing role of Corynebacterium ulcerans. Epidemiology \& Infection, Cambridge, v.138, n.11, p.1519-1530, 2010. DOI: https://doi.org/10.1017/s0950268810001895

WALKE, J. B.; HARRIS, R. N.; REINERT, L. K.; ROLLINS-SMITH, L. A.; WOODHAMS, D. C.. Social immunity in amphibians: evidence for vertical transmission of innate defenses. Biotropica, v.43, n.4, p.396-400, 2011. DOI: https://doi.org/10.1111/j.1744-7429.2011.00787.x

WALKE, J. B.; BECKER, M. H.; LOFTUS, S. C.; HOUSE, L. L.; CORMIER, G.; JENSEN, R. V.; BELDEN, L. K.. Amphibian skin may select for rare environmental microbes. The ISME Journal, Wageningen, v.8, n.11, p.2207-2217, 2014. DOI: https://doi.org/10.1038/ismej.2014.77

WENG, F. C. H.; SHAW, G. T. W.; WENG, C. Y.; YANG, Y. J.;
WANG, D.. Inferring microbial interactions in the gut of the Hong Kong whipping frog (Polypedates megacephalus) and a validation using probiotics. Frontiers in Microbiology, Lausanne, v.8, n.525, p.1-11, 2017. DOI: https://doi.org/10.3389/fmicb.2017.00525

WOODHAMS, D. C.; VREDENBURG, V. T.; SIMON, M. A.; BILLHEIMER, D.; SHAKHTOUR, B.; SHYR, Y.; BRIGGS, C. J.; ROLLINS-SMITH, L. A.; HARRIS, R. N.. Symbiotic bacteria contribute to innate immune defenses of the threatened mountain yellow-legged frog, Rana muscosa. Biological Conservation, v.138, n.3-4, p.390-398, 2007a. DOI: https://doi.org/10.1016/j.biocon.2007.05.004

WOODHAMS, D. C.; ROLLINS-SMITH, L. A.; ALFORD, R. A.; SIMON, M. A.; HARRIS, R. N.. Innate immune defenses of amphibian skin: antimicrobial peptides and more. Animal Conservation, v.10, n.4, p.425-428, 2007b. DOI: https://doi.org/10.1111/j.1469-1795.2007.00150.x

WOODHAMS, D. C.; BRANDT, H.; BAUMGARTNER, S.; KIELGAST, J.; KÜPFER, E.; TOBLER, U.; DAVIS, L. R.; SCHMIDT, B. R.; BEL, C.; HODEL, S.; KNIGHT, R.; MCKENZIE, V.. Interacting symbionts and immunity in the amphibian skin mucosome predict disease risk and probiotic effectiveness. PLoS One, San Francisco, v.9, n.4, p.e96375, 2014. DOI:

https://dx.doi.org/10.1371/journal.pone.0096375

WOODHAMS, D. C.; LABUMBARD, B. C.; BARNHART, K. L.; BECKER, M. H.; BLETZ, M. C.; ESCOBAR, L. A.; FLECHAS, S. V.; FORMAN, M. E.; IANNETTA, A. A.; JOYCE, M. D.; RABEMANANJARA, F; GRATWICKE, B.; VENCES, M.; MINBIOLE, K. P. C.. Prodigiosin, violacein, and volatile organic compounds produced by widespread cutaneous bacteria of amphibians can inhibit two Batrachochytrium fungal pathogens. Microbial Ecology, v.75, n.4, p.1049-1062, 2018. DOI: https://doi.org/10.1007/s00248-017-1095-7

YU, Z.; LIU, C.; FU, Q.; LU, G.; HAN, S.; WANG, L.; SONG, L.. The differences of bacterial communities in the tissues between healthy and diseased Yesso scallop (Patinopecten yessoensis). AMB Express, v.9, n.148, p.1-13, 2019. DOI: https://dx.doi.org/10.1186/s13568-019-0870-x

ZANEVELD, J. R.; BURKEPILE, D. E.; SHANTZ, A. A.; PRITCHARD, C. E.; MCMINDS, R.; PAYET, J. P.; WELSH, R.; CORREA, A. M. S.; LEMOINE, N. P.; ROSALES, S.; FUCHS, C.; MAYNARD, J. A.; THURBER, R. V.. Overfishing and nutrient pollution interact with temperature to disrupt coral reefs down to microbial scales. Nature Communications, v.7, n.11833, 2016. DOI: https://doi.org/10.1038/ncomms11833

ZUG, G. R.; ZUG, P. B.. The Marine Toad, Bufo marinus: A Natural History Resume of Native Populations. Smithsonian Contributions to Zoology, n.284, p.1-58, 1979. DOI: https://doi.org/10.5479/si.00810282.284

A CBPC - Companhia Brasileira de Produção Científica (CNPJ: 11.221.422/0001-03) detém os direitos materiais desta publicação. Os direitos referem-se à publicação do trabalho em qualquer parte do mundo, incluindo os direitos às renovações, expansões e disseminações da contribuição, bem como outros direitos subsidiários. Todos os trabalhos publicados eletronicamente poderão posteriormente ser publicados em coletâneas impressas sob coordenação da Sustenere Publishing, da Companhia Brasileira de Produção Científica e seus parceiros autorizados. Os (as) autores (as) preservam os direitos autorais, mas não têm permissão para a publicação da contribuição em outro meio, impresso ou digital, em português ou em tradução. 